\title{
Chapter 5 \\ Technology Perception and Productivity Among Physicians in the New Norm Post-pandemic: A Dynamic Capabilities Perspective
}

\author{
Ewilly J. Y. Liew, Sharon G. M. Koh, Andrei O. J. Kwok, Y. H. Poh, \\ and Juliana A. French
}

\begin{abstract}
Healthcare service is experiencing a paradigm shift due to the COVID19 pandemic. The pandemic has caused unprecedented fatalities and taken a toll on medical resources globally. Researchers and healthcare professionals value how data accessibility and analytics can save lives. Developing countries are fast leveraging on the electronic medical record (EMR) system to enhance decision-making effectiveness and patient care. However, for many healthcare professionals, there remain unexplored possibilities of how the use of this 'normally' operational-centric EMR might change post-pandemic. We investigate the antecedents (perceived usefulness, perceived ease of use, habit) of the intention to use EMR, and its impact on dynamic capabilities and physician productivity pre- and post-pandemic, focusing on physicians who are at the frontline of Intensive Care Units (ICUs) in Malaysia. This study
\end{abstract}

\section{E. J. Y. Liew}

Department of Econometrics and Business Statistics, School of Business and Global Asia in the 21st Century Research Platform, Monash University Malaysia, Subang Jaya, Malaysia

e-mail: ewilly.liew@monash.edu

\section{S. G. M. Koh (凶)}

Department of Economics, School of Business and Global Asia in the 21st Century Research Platform, Monash University Malaysia, Subang Jaya, Malaysia

e-mail: koh.geokmay@monash.edu

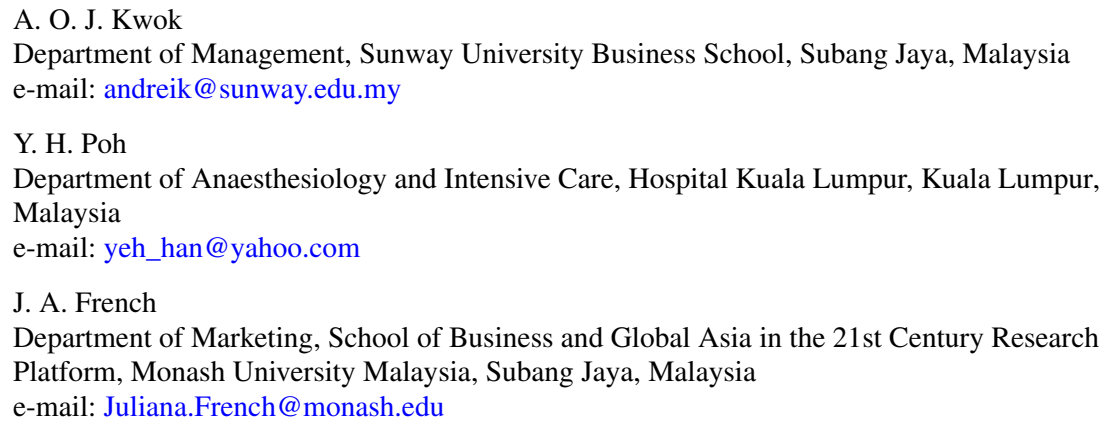

\section{J. A. French}

Department of Marketing, School of Business and Global Asia in the 21st Century Research Platform, Monash University Malaysia, Subang Jaya, Malaysia

e-mail: Juliana.French@monash.edu

J. Lee and S. H. Han (eds.), The Future of Service Post-COVID-19 Pandemic, Volume 1,

The ICT and Evolution of Work,

https://doi.org/10.1007/978-981-33-4126-5_5 
evidences two significant findings: (1) before the pandemic in the 'normal' condition of EMR use, technology perception has significant indirect impact on physician productivity via the key role of dynamic capabilities. However, (2) after the pandemic in the 'abnormal' condition, technology perception no longer has any significant impact on physician productivity though their intention to use EMR may have a very weak direct impact on their productivity. A key significant change in the new norm post-pandemic is that dynamic capabilities no longer mediate but strongly and directly impact physician productivity. This direct positive effect is much stronger than before the pandemic. Theoretically, the study is among the first few to integrate perspectives from information systems and dynamic capabilities to examine the impact of EMR use on physician dynamic capabilities for knowledge acquisition and deployment towards enhancing their productivity. The study also offers insights into how a pandemic could accelerate technology perception and contributes to the dynamic use of technology to aid physicians.

Keywords Electronic medical record - Intensive care unit • Information systems • Dynamic capabilities $\cdot$ Physician productivity $\cdot$ COVID-19 pandemic

\subsection{Introduction}

The novel coronavirus SARS-CoV-2 (COVID-19) outbreak has caused a sudden surge of patients that posed a new challenge to hospitals, especially the Intensive Care Unit (ICU) (Arabi et al. 2020). The overburdened healthcare service, in response to emergencies, has highlighted the indispensability of the electronic medical record ${ }^{1}$ (EMR) system as a coping mechanism for physician productivity (Wang et al. 2020). Hence, this study sets out to examine how the rapidly changing healthcare environment due to the COVID-19 pandemic has challenged physicians' technology perception and readiness as physicians have to adapt to the EMR system to improve their productivity purposefully (Cohen et al. 2020).

Since healthcare service is highly dependent on physician openness to adapt to new work processes, the transition from manual to the EMR system is more of a managerial concern than a technological consideration due to human resistance to change and potential interruption or complexity to the existing workflow operation (Zandieh et al. 2008; Nguyen et al. 2014). Specifically, in developing countries, the implementation of EMR system is still costly to most public hospitals. Thus, little is known about physician belief on how COVID-19 can accelerate the use of the EMR to aid decision-making, and the drivers of IT use behavior in the context of healthcare delivery (Lu et al. 2020).

\footnotetext{
${ }^{1}$ The EMR is a comprehensive patient record system which contain pertinent information on patients' past and present medical information. As such, in many instances the EMR system improves staff efficiency, accountability, and error reduction in hospitals as it systematically manages patients' clinical data.
} 
The study integrates theoretical perspectives from the information systems (IS) and dynamic capabilities literature. We combine some key constructs from two widely used models in the literature namely the Technology Acceptance model (TAM) and Unified Theory of Acceptance (UTAUT) to analyze the physicians' intention to use and ensuing behavior. Furthermore, the current COVID-19 pandemic presents bigger challenges to the healthcare service in terms of effectively responding to the crisis. As such, the dynamic capabilities literature presents a potential response in this turbulent environment.

First, we set out to examine the impact of the EMR use on physician productivity, mediated by physician dynamic capabilities for knowledge acquisition and deployment, during the switch from manual to electronic workflow operation at the onset of the EMR deployment in the hospital pre-pandemic (before the outbreak of COVID-19). Next, we compare the impact of the EMR use on physician productivity post-pandemic (after the outbreak of COVID-19). The secondary examination is intended to determine how the pandemic has impacted physician perspective on the use of the EMR to reveal insights into the importance of EMR that contributes to the acceleration of the digitization of healthcare services post-pandemic. Our results will critically capture lessons learned on the EMR use to leverage physician dynamic capabilities and physician productivity from a developing country perspective.

\subsection{Electronic Medical Record (EMR) System in Healthcare Service}

The COVID-19 pandemic has catalysed digitization in healthcare by highlighting the importance and accelerating the use of the EMR (Mahmood et al. 2020). Often, the role of physicians and patient care is inseparable ${ }^{2}$ within the healthcare service. For instance, a patient needs to explain the symptoms of the medical condition in order for a doctor to pronounce a correct diagnosis so the service is inseparable as the patient is physically present and involved in the service.

Additionally, quality healthcare service is associated with patient mortality and readmission rates, patient satisfaction with quality care or physical health, infrastructure, and availability of preventative care (Legatum Prosperity Index 2017). Although the EMR is gradually implemented in stages by hospitals in developing countries (Dornan et al. 2019; Fraser et al. 2005), the costs associated with healthcare technology investment has not been uniformly justified, often leading to slow adoption of the EMR (Terry et al. 2012).

As the EMR moves healthcare information and knowledge resources towards an integrated interface, effective use of the system would improve staff efficiency, accountability, and error reduction in hospitals as it systematically manages patient

\footnotetext{
${ }^{2}$ In the literature, services are distinguished from products on the basis of intangibility, heterogeneity, inseparability and perishability or IHIP paradigm (Askedal and Skiftenes Flak 2017; Grove et al. 2003).
} 
clinical data (Williams and Boren 2008; Jha 2010). The use of the EMR reduces human error and improves medical diagnostics as physicians do not work in silos and are able to make better patient care decisions based on available online information (Noraziani et al. 2013). In this age of rapid medical advancement, physicians have to rely on reliable systems to ensure real-time access to information and enable regular communication between teams of multidisciplinary specialists involved in the care of a patient (Evans 2016). The EMR minimizes occurrences of biasness when physicians decide on a treatment course after making a definitive diagnosis or the consequences of a wrong diagnosis since physicians will not have to second guess their decisions since all decisions will be made objectively based on the data provided by the EMR (Scott et al. 2018; Bornstein and Emler 2001).

Despite the potential benefits of using the EMR, certain challenges in using the EMR system have also been highlighted in the literature (Fraser et al. 2005; Thakkar and Davis 2006). Physicians have described requiring longer working time learning to use the EMR effectively as most systems have multiple screens and navigation options. With an already heavy workload, physicians would prefer spending their time by the patient's bedside and getting more involved in the practical aspects of patient care (Dewa et al. 2014). Thus, many physicians tend to use the EMR system as an electronic paper record system and were unable to fully utilize the advanced functions of the EMR (Price et al. 2013).

\subsection{Theory and Hypotheses Development}

\subsubsection{Dynamic Capabilities Theory}

Rapid technological development presents an excellent potential for healthcare service organizations. However, the actual use of these technologies may be resisted by physicians for fear of changing their work processes, consequently affecting their productivity and job performance (Kankanhalli et al. 2016). This resistance from physicians may further impair the allocation of knowledge resources that would impact not only patient care but also socioeconomic outcomes for the healthcare organization. Existing literature often view technological infrastructure as a trajectory to effective knowledge management, thereby having a positive impact on productivity and job performance (Easterby-Smith and Prieto 2008). As such, knowledge management literature often relies on the dynamic capabilities perspective to explain "how best to manage organizations in dynamic and discontinuous environments" (Kankanhalli et al. 2016).

In one of the earliest papers on utilizing dynamic capabilities to enhance competitiveness in the healthcare industry, Sher and Lee (2004) emphasized the "importance of dynamic capabilities in a turbulent environment." Since the emergence of the COVID-19 pandemic, healthcare service organizations had to navigate the turbulent environment by frequently reconfigure their work processes to enhance performance. 
Without the right technological capabilities, the disruptive effects of the pandemic can create a severe liability to the healthcare service organization.

Dynamic capabilities are the ability of an organization to manage its vast resources in a rapidly changing environment, allowing for improvisations where necessary. The concept, first defined by Teece and Pisano (1994), was built on a resource-based view (Barney 1991) dealing with the evolutionary nature of resources and capabilities in a rapidly evolving environment. However, having resources advantage is necessary but not sufficient for gaining competitive advantages. Therefore, the enhancement of distinctive capabilities is essential to make better use of organizational resources (Wang and Ahmed 2007).

The development of dynamic capabilities can be understood as an evolving process based on the interaction between daily operations and knowledge-creating activities. It is not a one-off ad hoc problem-solving mechanism (Zahra et al. 2006). The enhancement of dynamic capabilities is an ongoing process that would redefine the knowledge base of organizations or individuals, which eventually would lead to value creation (Barreto 2010). Especially at the individual level, Rothaermel and Hess (2007) postulate that individuals interact with organizational supporting assets and processes to achieve improved performance. The heterogeneity of cognitive capability such as medical diagnosis evidenced support of "dynamic managerial capabilities for sensing, seizing, and reconfiguring, and explained their potential impact on strategic change of organizations" (Helfat and Peteraf 2015).

\subsubsection{A Unified Theory of Acceptance and Use of Technology (UTAUT2)}

The UTAUT2 model is an extension to the original technology acceptance model (TAM) and UTAUT model but refined to include consumer use context (Venkatesh et al. 2012). 'Perceived usefulness' and 'perceived ease of use' from TAM remain as main predictors in the UTAUT and UTAUT2 for behavioral intention to use (Venkatesh et al. 2011). However, the subsequent UTAUT models use different terminologies 'performance expectancy' and 'effort expectancy' while maintaining the same conceptual underpinning of the TAM constructs. Habit is one of the new key constructs incorporated into the UTAUT2 model. In line with Limayem et al. (2007), the authors define habit "as the extent to which people tend to perform behaviors automatically because of learning" (Venkatesh et al. 2012). As such, the authors posit that habit can influence technology perception and the intention to use a system.

This study included perceived usefulness (PU) and perceived ease of use (PEU) from the common TAM and UTAUT frameworks but excluded social influence (SI) and facilitating conditions (FC) postulated in the UTAUT frameworks. It is because our study took a person-centric approach in examining individual physicians' perceptions and focused on two different stages of the EMR use from adoption to postadoption. Furthermore, the sudden surge of patients, especially in the ICUs (Arabi 
et al. 2020), might affect both new and experienced physicians in their EMR use behaviors. Hence, we investigate the change in physicians' perceptions of using the EMR system from pre-pandemic to post-pandemic (after the outbreak of COVID-19).

\subsubsection{Conceptual Framework}

Based on the information systems and dynamic capabilities literature discussed above, the conceptual model is illustrated in Fig. 5.1. Accordingly, the study examines whether technology perception (perceived usefulness and perceived ease of use) as antecedents of the intention to use EMR, would also impact dynamic capabilities and physician productivity. Following Venkatesh et al. (2012), we added habit into the model as a direct antecedent of intention to use and a control variable to moderate the relationship between intention to use and physician productivity.

\subsubsection{Technology Perception on Intention to Use}

The information systems research identifies two technology perception successfully used to explain actual technology acceptance and system use (Venkatesh et al. 2003). Perceived usefulness (PU) and perceived ease of use (PEU) are two core beliefs in Davis' (1989) Technology Acceptance Model (TAM), one of the most widely used models in studying individual-level system adoption and use. Moreover, the conceptual underpinning of PU and PEU also incorporates into the UTAUT and UTAUT2 models (Venkatesh et al. 2003, 2012). In this study, PU is defined as the degree to which an individual physician believes that using an EMR would be useful to enhance job performance (Davis 1989). PEU is defined as the degree to which an individual physician believes that using an EMR would be easy and free from effort (Davis 1989). PU has always been the primary determinant of system adoption and use.

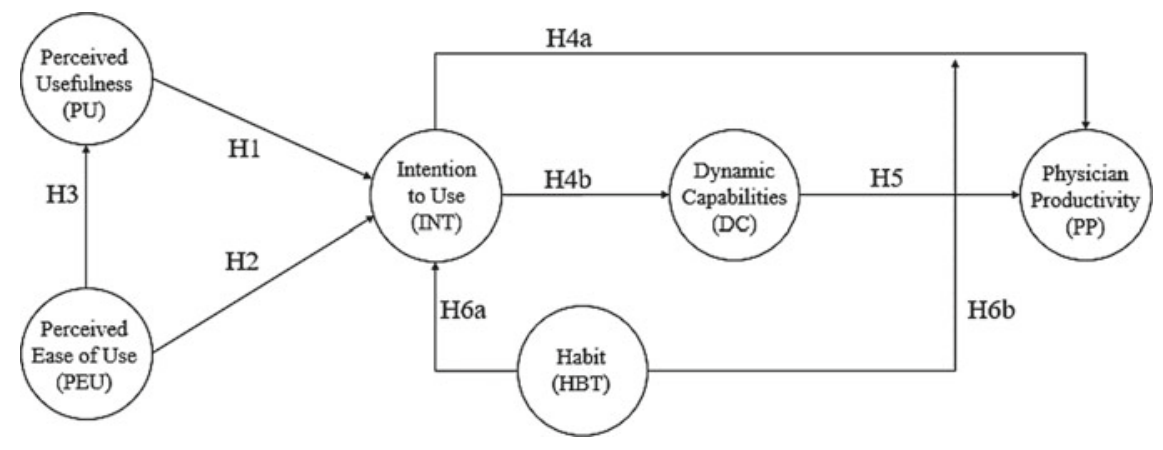

Fig. 5.1 Conceptual model 
With an already busy workload, the implementation of the EMR may exacerbate the burden on physicians who show significant concerns over their responsibilities for medical decisions, clinical documentation, patient care, administration issues, and research especially in teaching hospitals (Bhargava and Mishra 2014; Sykes et al. 2011). The field survey by Ayanso et al. (2015) demonstrates that PU directly impacts the physicians' continuance intention. This study postulates that physicians who find the EMR useful for their operational routine and performance benefits will use the system regularly (Dobrzykowski and Tarafdar 2017). Thus, hypotheses 1 are as follows:

H1: Perceived usefulness (PU) has a direct positive effect on intention to use the EMR (INT).

The design of most EMRs could be cumbersome with multiple viewing screens and rigid navigation options that are not customized nor user-friendly for physicians. The initial learning time may put off physicians in transiting from their habitual use of the manual system to the new EMR. Furthermore, some physicians may perceive that learning to use and master a new EMR is a bad trade-off as they would rather spend their time being more involved in-patient care. Although Sykes et al. (2011) find that only PU is a key factor influencing physicians' use of the EMR, the study also points out the potential effect of PEU on the intention to use. Gagnon et al. (2014) evidence that PEU is positively associated with the physicians' intention to use the EMR. This study postulates that physicians who find it easy and comfortable to use the EMR would likely use it at least as regularly as they do now and for the foreseeable future (Price et al. 2013; Jha 2010). Thus, hypotheses 2 are as follows:

H2: Perceived ease of use (PEU) has a direct positive effect on intention to use the EMR (INT).

Davis (1989) and Venkatesh et al. (2003) discover that PEU can directly impact PU for technology adoption and use, but not otherwise. The positive correlation between PEU and PU is also observed for the intention to use EMR (Sykes et al. 2011). This study postulates that physicians who find it easy and comfortable to use the EMR would be likely to overcome the perceived difficulty in using it and willing to spend time learning to master any useful aspects of the system (Terry et al. 2012; Tierney et al. 2013). Hence, hypothesis 3 is as follows:

H3: Perceived ease of use (PEU) has a direct positive effect on perceived usefulness (PU) of using the EMR.

The intention to use EMR is measured by behavioral intention, which accounts for the internal behavioral determinants of physicians, as the degree to which conscious plan is formulated in the mind to use or not to use EMR in the future (Warshaw and Davis 1985). Given the integral role of EMR in the physicians' decision-making process, the intention to use EMR beyond adoption could directly affect physicians' dynamic capabilities and productivity. This study postulates that a positive intention to use the EMR would have a direct impact on physicians' abilities to acquire and 
learn new knowledge from other physicians' inputs to the system, integrate and coordinate available information resources to improve decision quality on critical patients. Furthermore, a positive intention to use the EMR would also directly affect physicians' productivity as they synthesize information from multiple sources on the EMR and make patient treatment decisions efficiently, which can be helpful to other physicians (Nguyen et al. 2014; Furukawa 2011). Hence, hypothesis 4a and 4b are as follows:

H4a: The intention to use EMR (INT) has a direct positive effect on dynamic capabilities (DC).

H4b: The intention to use EMR (INT) has a direct positive effect on physician productivity $(\mathrm{PP})$.

\subsubsection{Dynamic Capabilities on Physician Productivity}

In the healthcare industry, physicians should not only be able to perform their duties (operational capabilities) but comprehend changes in their external environment, seize the opportunity to utilize technology and knowledge resources or competencies to meet new challenges (Teece 2007). The quality of the job performed by physicians would directly ensure the quality of healthcare services provided, which may further impact patient care and socioeconomic outcomes at the macro-level.

Furthermore, as learning is central to developing dynamic capabilities, physicians often "learn by doing" and are called to provide accurate diagnosis involving lifeand-death decisions (Cohen and Levinthal 1990). It is as they learn by accessing explicit patient data and assessing these data based on tacit medical knowledge that they can articulate sound diagnosis on patients. Trial and error, improvisation, and imitation (Zahra et al. 2006) may also be useful in the process of reconfiguring knowledge resources and competencies to address the medical conditions at hand better. Physicians are learning and consciously developing their dynamic capabilities for better productivity and job performance when they are engaging in such knowledge-creating activities (Easterby-Smith and Prieto 2008).

The EMR helps to facilitate patient information and consolidate multidisciplinary knowledge resources in the hospital. This study postulates that using the EMR would be likely to enhance physicians' dynamic capabilities for knowledge acquisition and deployment in practical aspects of patient care, and thus having a positive impact on physician productivity (Agwunobi and Osborne 2016). Hence, hypothesis 5 is as follows.

H5: Dynamic capabilities (DC) has a direct positive effect on physician productivity $(\mathrm{PP})$. 


\subsubsection{Habit, Intention to Use and Physician Productivity}

The UTAUT2 model incorporated habit as a perceptual construct that reflects prior experiences (Venkatesh et al. 2012). Physicians form different levels of habit depending on the extent of their interaction and familiarity when learning to use an EMR and receiving feedback from prior experiences (Limayem et al. 2007). Accordingly, habit is postulated as one of the "key drivers of behavior" (Venkatesh et al. 2012) that would directly impact intention to use as well as negatively moderating the effect of intention on actual use behaviors. Such operationalization of habit is consistent with the UTAUT2 model, which believes that habit influences behavioral intention and increasing habit would diminish the effect of intention on actual use (Limayem et al. 2007; Venkatesh et al. 2012). Thus, it is necessary to investigate not only the positive effect of habit on the intention to use EMR but also whether habit would weaken the intention to use EMR for physician's productivity. Hence, hypotheses $6 \mathrm{a}$ and $6 \mathrm{~b}$ are as follows:

H6a: Habit (HBT) has a direct positive effect on the intention to use EMR (INT).

H6b: Habit (HBT) negatively moderates the relationship between intention to use EMR (INT) and physician productivity (PP).

\subsection{Methodology}

\subsubsection{Data and Sampling Design}

This study is a subset of more extensive research conducted in the Intensive Care Units (ICUs) of four leading tertiary referral hospitals in Malaysia. These hospitals are directly involved in the screening and intensive care management of COVID-19 positive patients, Patients Under Investigation (PUI), and those with Severe Acute Respiratory Infection (SARI). The Malaysian Society of Intensive Care Medicine strives to provide optimal medical expertise and excellent patient care in every hospital.

The data were collected in two waves. The pre-pandemic data (wave 1) was collected in 2018, representing the 'normal' use of EMR while the post-pandemic data was collected from April-May 2020 (wave 2), representing the 'abnormal' use of EMR during the spike of COVID-19 cases in Malaysia. The study focuses on individual physicians who are at the frontline of interactions with the EMR reviewing patients' information, making decisions, executing treatments, and entering patients' updates into the system (Bhargava and Mishra 2014).

Clustered random sampling method was employed to collect data pre- and postpandemic, reaching out to all physicians (in the categories of specialists, medical officers, and house officers) who are directly involved with patient care in the ICUs of 
the identified hospitals. The sampling frame contains a list of all physicians working in the ICUs during the period of our data collection. The physicians were given the option to complete either a paper-based or an online-based questionnaire during the pre-pandemic survey. During the post-pandemic survey, we reached out to physicians who had previously completed the first wave of the survey as well as other physicians who were newly added to the sampling frame. All respondents were given the only option of an online-based questionnaire during the post-pandemic survey. Our survey questions were part of a larger survey administrated in the hospitals.

A total of 67 valid responses and 55 valid responses were obtained from prepandemic and post-pandemic waves, respectively, representing a majority of the ICU physicians in the country. Results from the cross-tabulations and independent samples $t$-test (see Table 5.1) indicated no significant differences of the sample characteristics were found between pre-pandemic respondents (wave $1, n=67$ ) and post-pandemic respondents (wave $2, n=55$ ). The final sample consists of 122 physicians.

Table 5.1 Sample characteristics: pre-pandemic and post-pandemic comparison

\begin{tabular}{|c|c|c|c|c|c|}
\hline \multirow[t]{2}{*}{ Variables } & \multirow[t]{2}{*}{ Subgroups } & Pre & Post & Total & \multirow[t]{2}{*}{$p$-value } \\
\hline & & 67 & 55 & 122 & \\
\hline Age (year) & & $33.45 \pm 3.08$ & $32.45 \pm 3.25$ & & 0.087 n.s. \\
\hline \multirow[t]{4}{*}{ Gender } & \multirow[t]{2}{*}{ Male } & 34 & 33 & 67 & 0.283 n.s. \\
\hline & & $50.7 \%$ & $60.0 \%$ & $54.9 \%$ & \\
\hline & \multirow[t]{2}{*}{ Female } & 33 & 22 & 55 & \\
\hline & & $49.3 \%$ & $40.0 \%$ & $45.1 \%$ & \\
\hline \multirow[t]{8}{*}{ Ethnicity } & \multirow[t]{2}{*}{ Malay } & 20 & 19 & 39 & 0.669 n.s. \\
\hline & & $29.9 \%$ & $34.5 \%$ & $32.0 \%$ & \\
\hline & \multirow[t]{2}{*}{ Chinese } & 34 & 26 & 60 & \\
\hline & & $50.7 \%$ & $47.3 \%$ & $49.2 \%$ & \\
\hline & \multirow[t]{2}{*}{ Indian } & 12 & 9 & 21 & \\
\hline & & $17.9 \%$ & $16.4 \%$ & $17.2 \%$ & \\
\hline & \multirow[t]{2}{*}{ Others } & 1 & 1 & 2 & \\
\hline & & $1.5 \%$ & $1.8 \%$ & $1.6 \%$ & \\
\hline \multirow[t]{6}{*}{ Role } & \multirow[t]{2}{*}{ Specialist } & 10 & 9 & 19 & 0.953 n.s. \\
\hline & & $14.9 \%$ & $16.4 \%$ & $15.6 \%$ & \\
\hline & \multirow[t]{2}{*}{ Medical Officer } & 55 & 44 & 99 & \\
\hline & & $82.1 \%$ & $80.0 \%$ & $81.1 \%$ & \\
\hline & \multirow[t]{2}{*}{ House Officer } & 2 & 2 & 4 & \\
\hline & & $3.0 \%$ & $3.6 \%$ & $3.3 \%$ & \\
\hline
\end{tabular}

Continuous values: mean \pm standard deviation. Categorical values: frequency $\mathrm{n}(\%)$

Level of significance: ${ }^{\text {n.s. }} p$ not significant, ${ }^{* *} p<0.05, * * * p<0.01$ 


\subsubsection{Content Validity}

To ensure the content validity of the multi-item scales used in the study, readily established instruments were adapted from prior research. Instruments measuring perceived ease of use (PEU) and perceived usefulness (PU) of using the EMR were obtained from Sykes et al. (2011). Sample items include "Learning to operate EMR would be easy for me" and "I believe EMR would be useful in my job". Habit (HBT) and intention to use EMR (INT) were measured using Venkatesh et al.'s (2012) UTAUT2 instruments such as "The use of EMR has become a habit for me" and "I intend to use EMR for the foreseeable future". Instruments measuring dynamic capabilities enhancement (DC) were obtained from Sher and Lee (2004). Sample items include "EMR enhances learning effectiveness of new knowledge" and "EMR enhances decision quality". Instruments measuring physician productivity (PP) were obtained from Bhargava and Mishra (2014). The sample item includes "EMR allows me to make patent treatment decisions efficiently". All items were measured on a 7-point Likert scale except for PP, which was measured on a 5-point Likert scale (refer to Appendix for full list of survey instruments).

\subsubsection{Results}

The empirical results were obtained from a multivariate analysis based on the partial least square structural equation modeling technique (PLS-SEM). The SmartPLS 3 software was used to confirm the measurement model and estimate the structural model (Ringle et al. 2015). The PLS-SEM is useful in handling models with small sample size and makes no distributional assumptions (Hair et al. 2017). The measurement model and structural model were also re-analyzed using a bootstrapping procedure of 5000 resamples to prevent overestimating the test statistics and increase estimation confidence based on the distribution-free sampling method (Hair et al. 2017).

\subsubsection{Measurement Model}

The measurement model was evaluated to ensure for construct reliability, convergent validity, and discriminant validity (see Table 5.2). The construct reliability and convergent validity were ascertained with all item loadings above 0.708 , composite reliability (CR) higher than the threshold value of 0.70 , and average variance extracted (AVE) higher than the threshold value of 0.50 . Sufficient discriminant validity was also ascertained based on Henseler et al.'s (2015) heterotrait-monotrait ratio of correlations (HTMT). All inter-construct correlations were lower than the 
Table 5.2 Convergent validity and discriminant validity

\begin{tabular}{|c|c|c|c|c|c|c|c|}
\hline \multicolumn{3}{|c|}{ Convergent Validity } & \multicolumn{5}{|c|}{ Discriminant Validity } \\
\hline & CR & AVE & PU & PEU & HBT & INT & DC \\
\hline PU & 0.966 & 0.904 & & & & & \\
\hline PEU & 0.942 & 0.803 & \begin{tabular}{|l|}
0.835 \\
{$[.758, .901]$}
\end{tabular} & & & & \\
\hline HBT & 0.906 & 0.707 & $\begin{array}{l}0.514 \\
{[.363, .648]}\end{array}$ & $\begin{array}{l}0.707 \\
{[.601, .797]}\end{array}$ & & & \\
\hline INT & 0.961 & 0.925 & $\begin{array}{l}0.796 \\
{[.706, .872]}\end{array}$ & $\begin{array}{l}0.736 \\
{[633, .826]}\end{array}$ & $\begin{array}{l}0.742 \\
{[.620, .846]}\end{array}$ & & \\
\hline $\mathrm{DC}$ & 0.955 & 0.680 & $\begin{array}{l}0.661 \\
{[.451, .833]}\end{array}$ & $\begin{array}{l}0.592 \\
{[.366, .784]}\end{array}$ & $\begin{array}{l}0.425 \\
{[.254, .589]}\end{array}$ & $\begin{array}{l}0.586 \\
{[.378, .759]}\end{array}$ & \\
\hline PP & 0.887 & 0.725 & $\begin{array}{l}0.631 \\
{[.380, .837]}\end{array}$ & $\begin{array}{l}0.522 \\
{[.271, .752]}\end{array}$ & $\begin{array}{l}0.412 \\
{[.233, .603]}\end{array}$ & $\begin{array}{l}0.583 \\
{[.341, .783]}\end{array}$ & $\begin{array}{l}0.835 \\
{[.727, .910]}\end{array}$ \\
\hline
\end{tabular}

Note PU: perceived usefulness; PEU: perceived ease of use; HBT: habit, INT: intention to use; DC: dynamic capabilities; PP: physician productivity

threshold value of 0.85 based on $H T M T_{.85}$ criterion (Kline 2011). None of the twotailed $90 \%$ bias-corrected confidence intervals of the HTMT contains the value of one (Henseler et al. 2015).

\subsubsection{Structural Model}

The structural model explicates the hypothesized relationships between antecedents (perceived usefulness (PU), perceived ease of use (PEU), habit (HBT)) of the intention to use EMR (INT), and its impact on dynamic capabilities (DC) and physician productivity (PP) pre- and post-pandemic. Inferences were drawn based on bootstrapped $t$-statistics at the specified $1 \%, 5 \%$, and $10 \%$ levels of significance. Overall, the model explained $75.4 \%$ (pre) and $63.1 \%$ (post) variations of INT, $56.9 \%$ (pre) and $4.8 \%$ (post) variations of DC, $59.0 \%$ (pre) and $61.1 \%$ (post) variations of PP. Table 5.3 provides a summary of the magnitude and significance of direct path coefficients that reflect the hypothesized relationships in this study, comparing prepandemic and post-pandemic models. Table 5.4 further provides interpretation of our results.

The measurement invariance of the composite models (MICOM) procedure was performed to ascertain the presence of observed heterogeneity in the study. The MICOM established that our empirical model achieves configural invariance and composite invariance based on 1000 permutations with two-tailed 95\% confidence intervals. The MICOM results indicated that the same construct was understood and assessed in a similar way across both groups (Chan 2011), although data collection 
Table 5.3 Results of hypothesized relationships (pre-and post-pandemic)

\begin{tabular}{|c|c|c|c|c|c|c|c|}
\hline \multirow[b]{2}{*}{$\begin{array}{l}\text { Hypothesized } \\
\text { relationships }\end{array}$} & \multicolumn{3}{|l|}{ Pre-pandemic } & \multicolumn{3}{|c|}{ Post-pandemic } & \multirow{2}{*}{$\begin{array}{l}\text { Path } \\
\text { coefficients } \\
\text { (pre- vs. } \\
\text { post-pandemic } \\
\text { comparison) }\end{array}$} \\
\hline & $\begin{array}{l}\text { Path } \\
\text { coefficients }\end{array}$ & $\begin{array}{l}\text { Effect } \\
\text { size } \\
f^{2}\end{array}$ & VIF & $\begin{array}{l}\text { Path } \\
\text { coefficients }\end{array}$ & $\begin{array}{l}\text { Effect } \\
\text { size } \\
f^{2}\end{array}$ & VIF & \\
\hline $\mathrm{H} 1: \mathrm{PU} \rightarrow \mathrm{INT}$ & $\begin{array}{l}0.588 \\
(4.774)^{* * * *}\end{array}$ & 0.544 & 2.699 & $\begin{array}{l}0.445 \\
(3.172)^{* * * *}\end{array}$ & 0.225 & 2.527 & $\begin{array}{l}-0.142 \\
(0.434)^{\text {n.s. }}\end{array}$ \\
\hline $\mathrm{H} 2: \mathrm{PEU} \rightarrow \mathrm{INT}$ & $\begin{array}{l}0.021 \\
(0.158)^{\text {n.s. }}\end{array}$ & 0.000 & 4.063 & $\begin{array}{l}-0.099 \\
(0.636)^{\text {n.s. }}\end{array}$ & 0.011 & 2.561 & $\begin{array}{l}-0.121 \\
(0.546)^{\text {n.s. }}\end{array}$ \\
\hline H3: PEU $\rightarrow$ PU & $\begin{array}{l}0.784 \\
(14.547) * * * \\
\end{array}$ & 1.598 & 1.000 & \begin{tabular}{|l}
$\mathbf{0 . 7 6 0}$ \\
$(10.687)^{* * * *}$ \\
\end{tabular} & 1.367 & 1.000 & $\begin{array}{l}-0.024 \\
(0.808)^{\text {n.s. }}\end{array}$ \\
\hline $\mathrm{H} 4 \mathrm{a}: \mathrm{INT} \rightarrow \mathrm{DC}$ & $\begin{array}{l}0.759 \\
(13.293) * * * *\end{array}$ & 1.357 & 1.000 & $\begin{array}{l}0.255 \\
(1.179)^{\text {n.s. }}\end{array}$ & 0.070 & 1.000 & $\begin{array}{l}-0.504 \\
(\mathbf{0 . 0 0 7})^{* * * *}\end{array}$ \\
\hline H4b: INT $\rightarrow$ PP & $\begin{array}{l}-0.005 \\
(0.034)^{\text {n.s. }}\end{array}$ & 0.000 & 3.710 & $\begin{array}{l}0.266 \\
(1.297)^{*}\end{array}$ & 0.072 & 2.708 & $\begin{array}{l}0.271 \\
(0.283)^{\text {n.s. }}\end{array}$ \\
\hline $\mathrm{H} 5: \mathrm{DC} \rightarrow \mathrm{PP}$ & $\begin{array}{l}0.562 \\
(5.121)^{* * * *}\end{array}$ & 0.347 & 2.362 & $\begin{array}{l}0.769 \\
(4.308) * * * *\end{array}$ & 1.399 & 1.175 & $\begin{array}{l}0.208 \\
(0.356)^{\text {n.s. }}\end{array}$ \\
\hline $\begin{array}{l}\text { H6a: HBT } \rightarrow \\
\text { INT }\end{array}$ & $\begin{array}{l}0.412 \\
(3.471)^{* * * *}\end{array}$ & 0.367 & 1.963 & $\begin{array}{l}0.543 \\
(5.900) * * * *\end{array}$ & 0.521 & 1.621 & $\begin{array}{l}0.131 \\
(0.389)\end{array}$ \\
\hline $\begin{array}{l}\text { H6b: INT*HBT } \\
\rightarrow \text { PP }\end{array}$ & \begin{tabular}{|l}
-0.198 \\
$(3.455)^{* * * *}$
\end{tabular} & 0.177 & - & $\begin{array}{l}0.075 \\
(0.893)^{\text {n.s. }}\end{array}$ & 0.020 & - & $\begin{array}{l}0.274 \\
(0.005) * * *\end{array}$ \\
\hline
\end{tabular}

Note Significance level based on bootstrapped $t$-statistics: $* * * p<0.01, * * p<0.05, * p<0.10,{ }^{\text {n.s. }} p$ non-significant. Cohen's $f^{2}$ effect size thresholds: Large $>0.35$, medium $>0.15$, small $>0.02$. Most of the variance inflation factors (VIF) were below the threshold value of 3.00 and the VIF on $\mathrm{H} 2$ : $\mathrm{PEU} \rightarrow \mathrm{INT}$ was still below the less stringent threshold value of 5.00

was conducted in two different time-periods. Thus, the respondents from the prepandemic group and post-pandemic group measuring the same construct were validated (Bialosiewicz et al. 2013). The comparison between pre- and post-pandemic empirical models was also justified and would be meaningful.

Sufficient predictive relevance was obtained to generalize our empirical model to other studies with a similar context. Results from the blindfolding and PLSPredict procedures show that all constructs in the model have cross-validated redundancy $Q^{2}$ values higher than the threshold of zero (Hair et al. 2017). The 10-fold crossvalidation also confirmed predictive relevance of the PLS-SEM model with all $Q^{2}$ values greater than zero, and most testing errors (RMSE, MAE, and MAPE) lower than the linear model prediction.

The empirical results supported four significant hypotheses in both the prepandemic and post-pandemic models, namely H1: PU $\rightarrow$ INT, H3: PEU $\rightarrow$ PU, H5: DC $\rightarrow$ PP and H6a: HBT $\rightarrow$ INT. Furthermore, two hypotheses show significant changes post-pandemic, H4a: INT $\rightarrow$ DC and H6b: INT*HBT $\rightarrow$ PP, considering physician new experience in the ICUs. We demonstrate that: 
Table 5.4 Interpretation of results (pre- and post-pandemic)

\begin{tabular}{|c|c|c|c|c|}
\hline $\begin{array}{l}\text { Hypothesized } \\
\text { relationships }\end{array}$ & $\begin{array}{l}\text { Hypothesis } \\
\text { supported } \\
\text { (pre-pandemic) } \\
\text { Yes/No }\end{array}$ & $\begin{array}{l}\text { Hypothesis } \\
\text { supported } \\
\text { (post-pandemic) } \\
\text { Yes/No }\end{array}$ & $\begin{array}{l}\text { Significant changes } \\
\text { from pre- to } \\
\text { post-pandemic? } \\
\text { Yes/No }\end{array}$ & $\begin{array}{l}\text { Interpretation of results } \\
\text { (comparing pre- and } \\
\text { post-pandemic models } \\
\text { based on Table 5.2) }\end{array}$ \\
\hline $\mathrm{H} 1: \mathrm{PU} \rightarrow \mathrm{INT}$ & Yes & Yes & No & $\begin{array}{l}\text { PU remains a strong } \\
\text { predictor that has a direct } \\
\text { positive effect on INT }\end{array}$ \\
\hline $\mathrm{H} 2: \mathrm{PEU} \rightarrow \mathrm{INT}$ & No & No & No & $\begin{array}{l}\text { PEU remains a } \\
\text { non-significant predictor } \\
\text { that does not directly } \\
\text { affect INT }\end{array}$ \\
\hline H3: PEU $\rightarrow$ PU & Yes & Yes & No & $\begin{array}{l}\text { PEU remains having } \\
\text { strong but only indirect } \\
\text { positive effect on INT } \\
\text { via PU }\end{array}$ \\
\hline H4a: INT $\rightarrow$ DC & Yes & No & Yes & $\begin{array}{l}\text { Pre-pandemic: INT has a } \\
\text { very strong positive } \\
\text { effect on DC ( } \beta_{4 a} \text { pre } \\
0.759) \\
\text { Post-pandemic: this } \\
\text { effect of INT on DC has } \\
\text { shrunk significantly by } \\
0.504 \text { ( } \beta_{4 a} \text { post }= \\
0.255) \text {. Hence, INT no } \\
\text { longer has significantly } \\
\text { impact on DC }\end{array}$ \\
\hline H4b: INT $\rightarrow$ PP & No & No & No & $\begin{array}{l}\text { Pre-pandemic: INT did } \\
\text { not significantly impact } \\
\text { PP } \\
\text { Post-pandemic: INT has } \\
\text { a positive effect on PP } \\
\left(\beta_{4 b p o s t}=0.266\right) \text { but } \\
\text { this effect is weak and } \\
\text { only marginally } \\
\text { significant at } 10 \% \\
\text { significance level }\end{array}$ \\
\hline $\mathrm{H} 5: \mathrm{DC} \rightarrow \mathrm{PP}$ & Yes & Yes & No & $\begin{array}{l}\text { The direct effect of DC } \\
\text { on PP is the only } \\
\text { relationship that remains } \\
\text { consistently significant } \\
\text { at the post-adoption } \\
\text { stage, from pre- to } \\
\text { post-pandemic. In fact, } \\
\text { DC has a much stronger } \\
\text { direct positive impact on } \\
\mathrm{PP} \text {, moving from } \\
\text { pre-pandemic }\left(\beta_{5 \text { pre }}=\right. \\
0.562) \text { to post-pandemic } \\
\left(\beta_{5 \text { post }}=0.769\right)\end{array}$ \\
\hline
\end{tabular}


Table 5.4 (continued)

\begin{tabular}{|c|c|c|c|c|}
\hline $\begin{array}{l}\text { Hypothesized } \\
\text { relationships }\end{array}$ & $\begin{array}{l}\text { Hypothesis } \\
\text { supported } \\
\text { (pre-pandemic) } \\
\text { Yes/No }\end{array}$ & $\begin{array}{l}\text { Hypothesis } \\
\text { supported } \\
\text { (post-pandemic) } \\
\text { Yes/No }\end{array}$ & $\begin{array}{l}\text { Significant changes } \\
\text { from pre- to } \\
\text { post-pandemic? } \\
\text { Yes/No }\end{array}$ & $\begin{array}{l}\text { Interpretation of results } \\
\text { (comparing pre- and } \\
\text { post-pandemic models } \\
\text { based on Table 5.2) }\end{array}$ \\
\hline H6a: HBT $\rightarrow$ INT & Yes & Yes & No & $\begin{array}{l}\text { The direct positive effect } \\
\text { of HBT on INT is } \\
\text { comparably strong as } \\
\text { PU on INT }\end{array}$ \\
\hline $\begin{array}{l}\text { H6b: INT*HBT } \rightarrow \\
\text { PP }\end{array}$ & Yes & No & Yes & $\begin{array}{l}\text { Pre-pandemic: HBT } \\
\text { used to negatively } \\
\text { moderate the effect of } \\
\text { INT on PP pre-pandemic } \\
\text { ( } \beta_{6 b} \text { pre }=-0.198 \text { ) such } \\
\text { that intention to use } \\
\text { EMR diminishes with } \\
\text { increasing habit } \\
\text { Post-pandemic: the } \\
\text { negative moderating } \\
\text { effect of HBT has } \\
\text { become positive albeit } \\
\text { not significant. } \\
\text { Nevertheless, the change } \\
\text { of effect from pre- to } \\
\text { post-pandemic has } \\
\text { significantly increased } \\
\text { by } 0.274\end{array}$ \\
\hline
\end{tabular}

i. Pre-pandemic: technology perceptions (perceived usefulness, perceived ease of use, and habit) significantly result in strong intention to use EMR, but such an intention did not have significant direct impact on physician productivity. Furthermore, increasing habit would diminish the effect of intention on physician productivity such that the use of EMR would become automatic with more experiences in using the EMR (significant negative moderating effect). A key relationship during the pre-pandemic use of EMR is that dynamic capabilities strongly and fully mediates ${ }^{3}$ the effect from intention to physician productivity $(\mathrm{INT} \rightarrow \mathrm{DC} \rightarrow \mathrm{PP}$ ). Thus, technology perceptions leading to intention to use EMR have only a significant indirect effect on physician productivity.

ii. Post-pandemic: technology perceptions (perceived usefulness, perceived ease of use, and habit) still significantly result in strong intention to use EMR. Such an intention now has a (very) weakly significant direct impact on physician productivity and no longer directly impact dynamic capabilities. Furthermore, habit no longer has any significant moderating effect on the relationship from intention to physician productivity. The key role of dynamic capabilities has also significantly changed from pre- to post-pandemic. Dynamic capabilities

\footnotetext{
${ }^{3}$ Full mediation: INT $\rightarrow$ DC $\rightarrow$ PP was significant but INT $\rightarrow$ PP not significant, therefore DC fully mediates the relationship from INT to PP such that INT has only significant indirect effect on PP with no significant direct effect.
} 
no longer mediates the effect from intention to physician productivity. Instead, dynamic capabilities now directly impact physician productivity, and this direct positive effect is much stronger post-pandemic (DC $\rightarrow \mathrm{PP})$.

\subsection{Healthcare Service Management Insights and Lessons Learned}

This study evidences two significant findings: (1) before the pandemic in the 'normal' condition of EMR use, technology perception has significant indirect impacts on physician productivity via the key role of dynamic capabilities. However, (2) after the pandemic in the 'abnormal' condition, the way physicians perceive the use of EMR no longer has any significant impact on their productivity; although their intention to use EMR may have a very weak direct impact on their productivity. A key significant change in the new norm post-pandemic is that dynamic capabilities no longer mediate but strongly and directly impact physician productivity. This direct positive effect is much stronger than before the pandemic. The COVID-19 pandemic has undoubtedly changed the way physicians perceive the use of EMR and provides insights into the knowledge of technology uses in hospitals.

Healthcare service organizations in developing countries can utilize physician dynamic capabilities as a source of competitive advantage (Agwunobi and Osborne 2016). The EMR organizes structured clinical data that helps physicians make informed decisions to provide accurate diagnosis during their performance in the ICU. Furthermore, the system is often dependent on the collective users of the system. It is because decisions in the ICU require consolidating patient data from various sources to allow physicians a holistic overview of patient condition. Huckman and Pisano (2006) examine procedures performed by 203 surgeons in Pennsylvania and find that a portion of surgeon performance is specific to the hospital. Their results suggest that physician performance is linked to the familiarity of systems in place, and their marginal productivity is not constant across firms. Thus, the implementation of the EMR justifies the cost of capital investment to healthcare service organisations and the cost of time and effort to physicians in learning the EMR system.

Our study provides practical implications in that enhancing physician dynamic capabilities can be leveraged as a source of competitive advantage in environments such as the ICU (pre-and post-pandemic). The increased use of the EMR will improve not only physician dynamic capabilities but also their productivity. Specifically, perceived usefulness and perceived ease of using the EMR would determine whether the enhancement of physician dynamic capabilities could be a source of their increased productivity. Physician productivity is strongly linked to how they utilize the EMR for building and integrating their competencies in daily operations of an intense situation in the ICU. 
A distinct advantage of implementing the EMR is to move away from information silos among physicians (who are specialists in their respective fields) towards an integrated interface. Decision-making in hospitals and especially in hospital units that require high vigilance such as the Intensive Care Unit (ICU), is a dynamic and complex process requiring sound medical knowledge from appropriate information sources (pre-and post-pandemic). Quick and accurate decisions may be the difference in preventing clinical deterioration or managing life-threatening events in the ICU. The EMR was put in place to aid such a decision-making process. It functions as a one-stop knowledge-based system that consolidates reliable patient data, credible physician notes, and up-to-date nursing care charts, besides current hospital practice on similar cases.

Although studies have found that computerized entries by specialists or physicians may initially slow down physician productivity during the transition period (Noraziani et al. 2013), this was not captured in our findings. Instead, physicians find that their productivity increased with the use of EMR. It can be accounted for by the heavy usage and familiarity with electronic devices pre- and post-pandemic. All these accounts for the potential advantages of implementing the EMR.

Habit was a moderator pre-pandemic, but not post-pandemic. Given the time-lapse between pre-pandemic and post-pandemic data, the introduction of the EMR could have altered habits across time. However, we could not verify within this study, thus allowing the opportunity for extended studies. Another limitation is that this study focuses on physician productivity and is less oriented towards how the improved service quality of physicians after EMR adoption could impact their patients preand post-pandemic.

\subsection{Conclusion}

This study presents findings that investigate the relationship between physician technology perception on using the EMR (perceived usefulness and perceived ease of use, dynamic capabilities enhancement for knowledge acquisition and deployment) and physician productivity in the Intensive Care Unit (ICU) pre and post-pandemic. This study contributes to the broader discussion on the role of dynamic capabilities in the healthcare sector. As healthcare service organizations migrate to the use of the EMR to digitize patient data and health records, physicians could make better decisions based on consolidated patient information. As Malaysia continues its efforts to flatten the COVID-19 pandemic curve, we are learning more and more about the systemic manifestations of the disease among the critically ill. The EMR has enabled physicians involved in the ICU care of COVID-19 patients to adopt a multidisciplinary approach with ease. In response to the UN's Sustainable Development Goal for "Good health and wellbeing," our study offers evidence of rapid leverage on the information technology platform to enhance good decision making and patient care in a developing country. 
Future research could extend the current model to examine the use of big data resources embedded in the EMR for effective decision making in critical care medicine. Given that the EMR implementation requires significant investment, future studies could determine the rate of return on investment, presently unexplored in this study. Furthermore, future studies may also explore the role of shared decisionmaking as a potential model for life-threatening diseases for patients in the ICU, as well as focus on how healthcare organizations could improve their physicians' EMR adoption towards patient care.

Acknowledgements We thank Dr. Melor Mansor (Head of Malaysian Anaesthetic and Intensive Care Services and Head of Dept of Anaesthesiology and Intensive Care, Hospital Kuala Lumpur), Dr. Mohd Rohisham bin Zainal Abidin (Head of Dept of Anaesthesiology and Intensive Care, Hospital Tengku Ampuan Rahimah Klang), Dr. Lee Chew Kiok (Consultant Intensivist, Hospital Sungai Buloh), and Dr. Premela Naidu a/p Sitaram (Head of Critical Care Services Unit, University Malaya Medical Centre) for allowing the study to be conducted in the respective Intensive Care Units. We also acknowledge that the study is supported by grant GA-MA-16-L01 of Global Asia in the 21st Century (GA21) Multidisciplinary Funding Platform from Monash University Malaysia.

We are also grateful for the feedback from the participants of the 18th International Conference on Electronic Business, ICEB, Guilin, China, December 2-6, 2018 on the first stage of the study (pre-pandemic) that enable the significant enrichment of this study (post-pandemic).

\section{Appendix: Full List of Survey Instruments}

\begin{tabular}{|c|c|c|}
\hline \multirow{4}{*}{$\begin{array}{l}\text { Perceived Usefulness } \\
\text { (Sykes et al. 2011) [7-point Likert } \\
\text { scale] }\end{array}$} & PU01 & I believe EMR would be useful in my job \\
\hline & PU02 & $\begin{array}{l}\text { Using EMR will enable me to } \\
\text { accomplish tasks more quickly }\end{array}$ \\
\hline & PU03 & $\begin{array}{l}\text { Using EMR will increase my } \\
\text { productivity }\end{array}$ \\
\hline & PU04 & $\begin{array}{l}\text { If I use EMR, I will increase my chances } \\
\text { of getting a raise }\end{array}$ \\
\hline \multirow{4}{*}{$\begin{array}{l}\text { Perceived Ease of Use } \\
\text { (Sykes et al. 2011) [7-point Likert } \\
\text { scale] }\end{array}$} & PEU01 & $\begin{array}{l}\text { My interaction with EMR would be } \\
\text { clear and understandable }\end{array}$ \\
\hline & PEU02 & $\begin{array}{l}\text { It would be easy for me to become } \\
\text { skillful at using EMR }\end{array}$ \\
\hline & PEU03 & I would find EMR to be easy to use \\
\hline & PEU04 & $\begin{array}{l}\text { Learning to operate EMR would be easy } \\
\text { for me }\end{array}$ \\
\hline \multirow{4}{*}{$\begin{array}{l}\text { Habit } \\
\text { (Venkatesh et al. 2012) [7-point Likert } \\
\text { scale] }\end{array}$} & НАBIT04 & $\begin{array}{l}\text { The use of EMR has become a habit for } \\
\text { me }\end{array}$ \\
\hline & HABIT05 & I am addicted to use EMR \\
\hline & HABIT06 & I must use EMR \\
\hline & HABIT07 & Using EMR has become natural to me \\
\hline
\end{tabular}


(continued)

\begin{tabular}{|c|c|c|}
\hline \multirow{3}{*}{$\begin{array}{l}\text { Intention to Use } \\
\text { (Venkatesh et al. 2012) [7-point Likert } \\
\text { scale] }\end{array}$} & INT01 & $\begin{array}{l}\text { I intend to continue using EMR in the } \\
\text { future }\end{array}$ \\
\hline & INT02 & $\begin{array}{l}\text { I intend to use EMR for the foreseeable } \\
\text { future }\end{array}$ \\
\hline & INT03 & $\begin{array}{l}\text { I intend to use EMR at least as regularly } \\
\text { as I do now }\end{array}$ \\
\hline \multirow{10}{*}{$\begin{array}{l}\text { Dynamic Capabilities } \\
\text { (Sher and Lee 2004) } \\
\text { [7-point Likert scale] }\end{array}$} & SLDC01 & $\begin{array}{l}\text { EMR enhances learning effectiveness of } \\
\text { new knowledge }\end{array}$ \\
\hline & SLDC02 & EMR enhances decision quality \\
\hline & SLDC03 & $\begin{array}{l}\text { EMR enhances capabilities of } \\
\text { communication and coordination }\end{array}$ \\
\hline & SLDC04 & EMR enhances responsiveness \\
\hline & SLDC05 & $\begin{array}{l}\text { EMR enhances integration in hospital } \\
\text { practice }\end{array}$ \\
\hline & SLDC06 & $\begin{array}{l}\text { EMR enhances accumulation of } \\
\text { knowledge }\end{array}$ \\
\hline & SLDC07 & $\begin{array}{l}\text { EMR enhances capabilities of resource } \\
\text { deployment }\end{array}$ \\
\hline & SLDC08 & EMR enhances patient relationship \\
\hline & SLDC09 & $\begin{array}{l}\text { EMR enhances trust with healthcare } \\
\text { providers }\end{array}$ \\
\hline & SLDC10 & $\begin{array}{l}\text { EMR enhances unimitability (unique) of } \\
\text { strategic knowledge asset }\end{array}$ \\
\hline \multirow{6}{*}{$\begin{array}{l}\text { Physician Productivity } \\
\text { (Bhargava and Mishra 2014) [5-point } \\
\text { Likert scale] }\end{array}$} & ВMPР01 & $\begin{array}{l}\text { EMR allows me to easily synthesize } \\
\text { information from multiple sources }\end{array}$ \\
\hline & ВMPP02 & $\begin{array}{l}\text { EMR allows me to make patient } \\
\text { treatment decisions efficiently }\end{array}$ \\
\hline & ВMPР03 & EMR interrupts my workflow \\
\hline & ВMPР04 & $\begin{array}{l}\text { I enter a lot of information about } \\
\text { patients, which can be helpful to other } \\
\text { physicians }\end{array}$ \\
\hline & BMPP05 & $\begin{array}{l}\text { On the balance, I do more information } \\
\text { entry than information synthesis using } \\
\text { EMR }\end{array}$ \\
\hline & ВMPР06 & $\begin{array}{l}\text { EMR has increased my documentation } \\
\text { time significantly }\end{array}$ \\
\hline
\end{tabular}




\section{Authors' Insight}

Healthcare service organizations in many developing countries choose to invest in the Electronic Medical Records (EMR) system to improve the productivity of healthcare professionals. The current COVID-19 pandemic is adding immense pressure on hospitals as more patients require healthcare services. The world was taken by surprise ever since cases of pneumonia in Wuhan, China were found to be due to a novel SARS-CoV2 virus now known as COVID-19. Over time, healthcare workers are learning more and more of the disease. What was initially thought to be a disease that targets the respiratory system primarily is now known also to have many other systemic manifestations. As of today, more than 1 million COVID-19 positive cases have been reported worldwide, with more than 100,000 associated deaths. Since the outbreak, healthcare service organizations had implemented strict control measures to protect healthcare workers and front liners. The EMR system becomes an indispensable tool as the patient's medical records, and history is available at the touch of a button. As the spectrum of manifestation of COVID-19 infection ranges from asymptomatic to severe illness leading to death, often times a multidisciplinary team approach is necessary. The EMR system enables information to be consolidated at a single point, allowing healthcare workers to have access to patient information such as hemodynamic parameters, laboratory results, radiological images, and input from other medical disciplines when necessary. The authors set out to investigate how the pandemic has changed physician use of the EMR system to improve their productivity in leading tertiary hospitals in Malaysia. For physicians in the Intensive Care Unit (ICU), accurate decisions on life and death are made quickly with the available information. The ability to make faster and more accurate decisions using the EMR system increases a doctor's productivity, which simultaneously benefits the patient as every decision made is for the welfare of the patient. In terms of service quality, understanding the impact of the EMR system on physicians will enable hospitals to serve the needs of their patients better. Findings indicate that physicians rely more on the EMR system post-pandemic since the system concurrently captures data on patients' risk and exposure to the pandemic. The 'new norm' requires the healthcare industry to continue to evolve with higher reliance on digital technology, thus leading to an acceleration of the digitization of healthcare services. Since the outbreak of COVID-19, the utilization of the EMR system to save patients has taken precedence over the deliberation about the cost of investing in the system. It has evidenced that the availability of the EMR system significantly enhances physician decision-making and improved their productivity, both factors which are vital to reducing the overburdened healthcare in such times of global health crisis. As Malaysia braces itself in anticipation of the next wave of COVID-19 infections or even outbreaks of other infectious diseases, the EMR system will prove an invaluable tool in the effort to anticipate, prepare, contain and curb the disease. It is our hope that the EMR system will one day be implemented throughout all the hospitals in Malaysia. 


\section{References}

Agwunobi, A., \& Osborne, P. (2016). Dynamic capabilities and healthcare: A framework for enhancing the competitive advantage of hospitals. California Management Review, 58(4), 141-161. https://doi.org/10.1525/cmr.2016.58.4.141.

Arabi, Y. M., Murthy, S., \& Webb, S. (2020). COVID-19: A novel coronavirus and a novel challenge for critical care. Intensive Care Medicine, 46, 833-836. https://doi.org/10.1007/s00134-020-059 $55-1$.

Askedal, K., \& Skiftenes Flak, L. (2017). Stakeholder contradictions in early stages of eHealth efforts. In Proceedings of the 50th Hawaii International Conference on System Sciences.

Ayanso, A., Herath, T. C., \& O'Brien, N. (2015). Understanding continuance intentions of physicians with electronic medical records (EMR): An expectancy-confirmation perspective. Decision Support Systems, 77, 112-122. https://doi.org/10.1016/j.dss.2015.06.003.

Barney, J. (1991). Firm resources and sustained competitive advantage. Journal of Management, 17(1), 99-120. https://doi.org/10.1177/014920639101700108.

Barreto, I. (2010). Dynamic capabilities: A review of past research and an agenda for the future. Journal of Management, 36(1), 256-280. https://doi.org/10.1177/0149206309350776.

Bhargava, H. K., \& Mishra, A. N. (2014). Electronic medical records and physician productivity: Evidence from panel data analysis. Management Science, 60(10), 2543-2562.

Bialosiewicz, S., Murphy, K., \& Berry, T. (2013). An introduction to measurement invariance testing: Resource packet for participants. American Evaluation Association, 1-37.

Bornstein, B. H., \& Emler, A. C. (2001). Rationality in medical decision making: A review of the literature on doctors' decision-making biases. Journal of Evaluation in Clinical Practice, 7(2), 97-107. https://doi.org/10.1046/j.1365-2753.2001.00284.x.

Chan, D. (2011). Advances in analytical strategies. In S. Zedeck (Ed.), APA handbooks in psychology®. APA handbook of industrial and organizational psychology. Building and developing the organization (1), 85-113. American Psychological Association. https://doi.org/10.1037/121 69-004.

Cohen, B. H., Busis, N. A., \& Ciccarelli, L. (2020). Coding in the world of COVID-19: Non-faceto-face evaluation and management care. CONTINUUM: Lifelong Learning in Neurology, 26(3), 785-798. https://doi.org/10.1212/CON.0000000000000874.

Cohen, W. M., \& Levinthal, D. A. (1990). Absorptive capacity: A new perspective on learning and innovation. Administrative Science Quarterly, 35, 128-152. https://doi.org/10.2307/2393553.

Davis, F. D. (1989). Perceived usefulness, perceived ease of use, and user acceptance of information technology. MIS Quarterly, 13, 319-340. https://doi.org/10.2307/249008.

Dewa, C. S., Loong, D., Bonato, S., Thanh, N. X., \& Jacobs, P. (2014). How does burnout affect physician productivity? A systematic literature review. BMC Health Services Research, 14, 325. https://doi.org/10.1186/1472-6963-14-325.

Dobrzykowski, D. D., \& Tarafdar, M. (2017). Linking electronic medical records use to physicians' performance: A contextual analysis. Decision Sciences, 48(1), 7-38. https://doi.org/10.1111/deci. 12219.

Dornan, L., Pinyopornpanish, K., Jiraporncharoen, W., Hashmi, A., Dejkriengkraikul, N., \& Angkurawaranon, C. (2019). Utilisation of electronic health records for public health in Asia: A review of success factors and potential challenges. BioMed Research International, 2019, 7341841. https:// doi.org/10.1155/2019/7341841.

Easterby-Smith, M., \& Prieto, I. M. (2008). Dynamic capabilities and knowledge management: An integrative role for learning? British Journal of Management, 19(3), 235-249. https://doi.org/10. 1111/j.1467-8551.2007.00543.x.

Evans, R. S. (2016). Electronic health records: Then, now, and in the future. Yearbook of Medical Informatics, 1(Suppl. 1), S48-S61. https://doi.org/10.15265/IYS-2016-s006.

Fraser, H., Biondich, P., Moodley, D., Choi, S., Mamlin, B., \& Szolovits, P. (2005). Implementing electronic medical record systems in developing countries. Journal of Innovation in Health Informatics, 13(2), 83-95. https://doi.org/10.14236/jhi.v13i2.585. 
Furukawa, M. F. (2011). Electronic medical records and the efficiency of hospital emergency departments. Medical Care Research and Review, 68(1), 75-95. https://doi.org/10.1177/107755871037 2108.

Gagnon, M.-P., Talla, P. K., Simonyan, D., Godin, G., Labrecque, M., Ouimet, M., et al. (2014). Electronic health record acceptance by physicians: Testing an integrated theoretical model. Journal of Biomedical Informatics, 48, 17-27. https://doi.org/10.1016/j.jbi.2013.10.010.

Grove, S. J., Fisk, R. P., \& John, J. (2003). The future of services marketing: Forecasts from ten services experts. Journal of Services Marketing, 17(2), 107-121. https://doi.org/10.1108/088760 40310467899.

Hair, Jr. J. F., Hult, G. T. M., Ringle, C., \& Sarstedt, M. (2017). A primer on partial least squares structural equation modeling (PLS-SEM) (2nd ed.). Sage publications: Thousand Oaks, CA.

Helfat, C. E., \& Peteraf, M. A. (2015). Managerial cognitive capabilities and the microfoundations of dynamic capabilities. Strategic Management Journal, 36(6), 831-850. https://doi.org/10.1002/ smj.2247.

Henseler, J., Ringle, C. M., \& Sarstedt, M. (2015). A new criterion for assessing discriminant validity in variance-based structural equation modeling. Journal of the Academy of Marketing Science, 43(1), 115-135. https://doi.org/10.1007/s11747-014-0403-8.

Huckman, R. S., \& Pisano, G. P. (2006). The firm specificity of individual performance: Evidence from cardiac surgery. Management Science, 52(4), 473-488. https://doi.org/10.1287/mnsc.1050. 0464.

Jha, A. K. (2010). Meaningful use of electronic health records: The road ahead. JAMA, 304(15), 1709-1710. https://doi.org/10.1001/jama.2010.1497.

Kankanhalli, A., Hahn, J., Tan, S., \& Gao, G. (2016). Big data and analytics in healthcare: Introduction to the special section. Information Systems Frontiers, 18(2), 233-235. https://doi.org/10. 1007/s10796-016-9641-2.

Kline, R. B. (2011). Convergence of structural equation modeling and multilevel modeling. In M. Williams, \& W. P. Vogt (Eds.), The SAGE handbook of innovation in social research methods (pp. 562-589). SAGE Publications Ltd: London. https://doi.org/10.4135/9781446268261.

Legatum Prosperity Index. (2017). https://www.prosperity.com/rankings.

Limayem, M., Hirt, S. G., \& Cheung, C. M. (2007). How habit limits the predictive power of intention: The case of information systems continuance. MIS Quarterly, 31, 705-737. https://doi. org/10.2307/25148817.

Lu, A., Cannesson, M., \& Kamdar, N. (2020). The tipping point of medical technology: Implications for the post-pandemic era. Anesthesia and Analgesia. http://doi.org/10.1213/ANE.000000000000 5040. http://doi.org/10.1213/ANE.0000000000005040.

Mahmood, S., Hasan, K., Carras, M. C., \& Labrique, A. (2020). Global preparedness against COVID-19: We must leverage the power of digital health. JMIR Public Health and Surveillance, 6(2), e18980.

Nguyen, L., Bellucci, E., \& Nguyen, L. T. (2014). Electronic health records implementation: An evaluation of information system impact and contingency factors. International Journal of Medical Informatics, 83(11), 779-796. https://doi.org/10.1016/j.ijmedinf.2014.06.011.

Noraziani, K., Nurul'Ain, A., Azhim, M., Eslami, S. R., Drak, B., Sharifa Ezat, W., et al. (2013). An overview of electronic medical record implementation in healthcare system: Lesson to learn. World Applied Sciences Journal, 25(2), 323-332. https://doi.org/10.5829/idosi.wasj.2013.25.02. 2537.

Price, M., Singer, A., \& Kim, J. (2013). Adopting electronic medical records: Are they just electronic paper records? Canadian Family Physician, 59(7), e322-e329.

Ringle, C. M., Wende, S., \& Becker, J.-M. (2015). SmartPLS 3. Hamburg: SmartPLS. http://www. smartpls.com. Accessed 5 January 2015.

Rothaermel, F. T., \& Hess, A. M. (2007). Building dynamic capabilities: Innovation driven by individual-, firm-, and network-level effects. Organization Science, 18(6), 898-921. https://doi. org/10.1287/orsc.1070.0291. 
Scott, I. A., Pillans, P. I., Barras, M., \& Morris, C. (2018). Using EMR-enabled computerized decision support systems to reduce prescribing of potentially inappropriate medications: A narrative review. Therapeutic Advances in Drug Safety, 9(9), 559-573. https://doi.org/10.1177/204209861 8784809.

Sher, P. J., \& Lee, V. C. (2004). Information technology as a facilitator for enhancing dynamic capabilities through knowledge management. Information \& Management, 41(8), 933-945. https:// doi.org/10.1016/j.im.2003.06.004.

Sykes, T. A., Venkatesh, V., \& Rai, A. (2011). Explaining physicians' use of EMR systems and performance in the shakedown phase. Journal of the American Medical Informatics Association, 18(2), 125-130. https://doi.org/10.1136/jamia.2010.009316.

Teece, D. (2007). Explicating dynamic capabilities: The nature and microfoundations of (sustainable) enterprise performance. Strategic Management Journal, 28(13), 1319-1350. https://doi. org/10.1002/smj.640.

Teece, D., \& Pisano, G. (1994). The dynamic capabilities of firms: An introduction. Industrial and Corporate Change, 3(3), 537-556.

Terry, A. L., Brown, J. B., Denomme, L. B., Thind, A., \& Stewart, M. (2012). Perspectives on electronic medical record implementation after two years of use in primary health care practice. The Journal of the American Board of Family Medicine, 25(4), 522-527. https://doi.org/10.3122/ jabfm.2012.04.110089.

Thakkar, M., \& Davis, D. C. (2006). Risks, barriers, and benefits of EHR systems: A comparative study based on size of hospital. Perspectives in Health Information Management, 3, 5.

Tierney, M. J., Pageler, N. M., Kahana, M., Pantaleoni, J. L., \& Longhurst, C. A. (2013). Medical education in the electronic medical record (EMR) era: Benefits, challenges, and future directions. Academic Medicine, 88(6), 748-752. https://doi.org/10.1097/ACM.0b013e3182905ceb.

Venkatesh, V., Morris, M. G., Davis, G. B., \& Davis, F. D. (2003). User acceptance of information technology: Toward a unified view. MIS Quarterly, 27, 425-478. https://doi.org/10.2307/300 36540 .

Venkatesh, V., Thong, J. Y., Chan, F. K., Hu, P. J. H., \& Brown, S. A. (2011). Extending the two-stage information systems continuance model: Incorporating UTAUT predictors and the role of context. Information Systems Journal, 21(6), 527-555. https://doi.org/10.1111/j.1365-2575. 2011.00373.x.

Venkatesh, V., Thong, J. Y., \& Xu, X. (2012). Consumer acceptance and use of information technology: Extending the unified theory of acceptance and use of technology. MIS Quarterly, 36, 157-178. https://doi.org/10.2307/41410412.

Wang, C., \& Ahmed, P. (2007). Dynamic capabilities: A review and research agenda. International Journal of Management Reviews, 9(1), 31-35. https://doi.org/10.1111/j.1468-2370.2007. 00201.x.

Wang, Z., Zheutlin, A. B., Kao, Y.-H., Ayers, K. L., Gross, S. J., Kovatch, P., et al. (2020). Analysis of hospitalized COVID-19 patients in the Mount Sinai Health System using electronic medical records (EMR) reveals important prognostic factors for improved clinical outcomes. medRxiv. https://doi.org/10.1101/2020.04.28.20075788.

Warshaw, P. R., \& Davis, F. D. (1985). Disentangling behavioral intention and behavioral expectation. Journal of Experimental Social Psychology, 21(3), 213-228. https://doi.org/10.1016/00221031(85)90017-4.

Williams, F., \& Boren, S. A. (2008). The role of the electronic medical record (EMR) in care delivery development in developing countries: a systematic review. Informatics in primary care, 16(2), 139-145. https://doi.org/10.14236/jhi.v16i2.685.

Zahra, S. A., Sapienza, H. J., \& Davidsson, P. (2006). Entrepreneurship and dynamic capabilities: A review, model and research agenda. Journal of Management Studies, 43(4), 917-955. https:// doi.org/10.1111/j.1467-6486.2006.00616.x.

Zandieh, S. O., Yoon-Flannery, K., Kuperman, G. J., Langsam, D. J., Hyman, D., \& Kaushal, R. (2008). Challenges to EHR implementation in electronic-versus paper-based office practices. Journal of General Internal Medicine, 23(6), 755-761. 

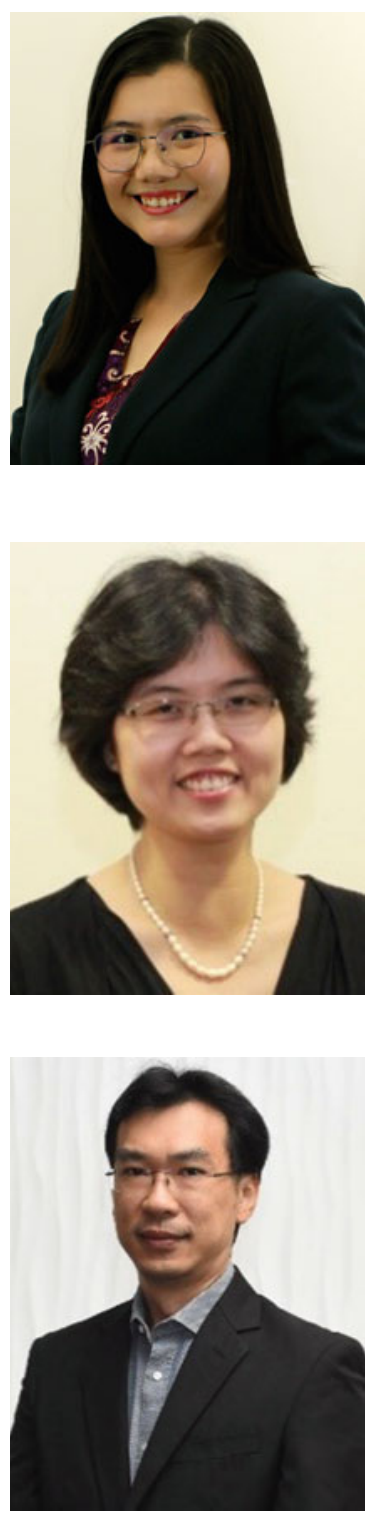

Dr. Ewilly J. Y. Liew is currently a lecturer and the Department Coordinator of the Econometrics and Business Statistics Department in Monash University Malaysia. She is a certified Enterprise Data Analyst (2017) and has served as the Department Academic Advisor for Business Analytics major from 2016 to 2018. She completed her Ph.D. in 2016 and is an avid data scientist certified with Monash Data Science Microcredential (2020). Her research focuses on interdisciplinary behavioral research related to creativity, social media technology, and knowledge creation in the fields of higher education and healthcare. Her research has won the overall best thesis and presentation (2010), the best paper in ISI Regional Statistics Conference (2014), and the Jeffrey Cheah Travel Grant Award for Southeast Asia Studies at Harvard University (Spring 2015).

Dr. Sharon Koh currently lectures at Monash University Malaysia. She holds a Ph.D. in Economics from Monash University. Her research lies in the impact of globalization on societies in Asia, particularly on inclusiveness, growth, and income inequality. She was a visiting research fellow at Harvard University (Fall 2015), and a recipient of an education excellence award in Melbourne. She has also obtained an international travel grant from the Asian Development Bank Institute to present her research in Tokyo.

Dr. Andrei Kwok completed his Ph.D. in Management at Monash University. His primary research focuses on decisionmaking behavior and organizational strategies. He has a secondary research interest in emerging technologies and interdisciplinary regional studies. Before joining academia, he has managed international R\&D teams in global technology firms. 

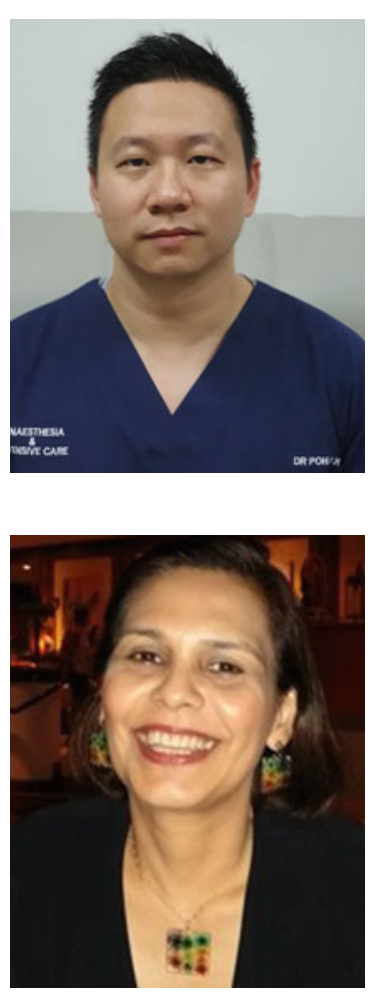

Dr. Poh Yeh Han is an Anaesthesiologist and Adult Intensive Care Medicine Fellow. He obtained his medical degree with a MB Bch BAO (NUI) in 2008 and qualified as an anaesthesiologist with a Master of Anaesthesiology (UM) in 2017. He is currently undergoing sub-specialty training in Adult Intensive Care Medicine.
Dr. Juliana French is a senior lecturer and the Department Coordinator of the Marketing Department in Monash University Malaysia. She is an early career researcher having completed her Ph.D. at the Business School, Monash University Malaysia in 2017. Her research interests lie in the area of consumption experiences and behavior, specifically the influence of culture on consumption behavior. These include the intersections of culture and marketplace, socio-historical patterning of consumption, consumption and identity, gender, culture in the healthcare industry and vulnerable communities. Juliana utilizes and specializes in a range of interpretive qualitative research. Juliana's industry background include advertising, television consultancy, sports marketing and management.

Open Access This chapter is licensed under the terms of the Creative Commons AttributionNonCommercial-NoDerivatives 4.0 International License (http://creativecommons.org/licenses/bync-nd/4.0/), which permits any noncommercial use, sharing, distribution and reproduction in any medium or format, as long as you give appropriate credit to the original author(s) and the source, provide a link to the Creative Commons licence and indicate if you modified the licensed material. You do not have permission under this licence to share adapted material derived from this chapter or parts of it.

The images or other third party material in this chapter are included in the chapter's Creative Commons licence, unless indicated otherwise in a credit line to the material. If material is not included in the chapter's Creative Commons licence and your intended use is not permitted by statutory regulation or exceeds the permitted use, you will need to obtain permission directly from the copyright holder.

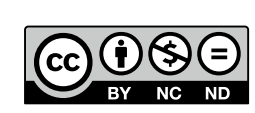

